01,07

\title{
Исследование прочности титанового сплава Ti-6Al-4V в условиях ударных и импульсных воздействий
}

\author{
(ㄷ А.Д. Евстифреев ${ }^{1}$, Ю.В. Петров ${ }^{1,2}$, Н.А. Казаринов ${ }^{1}$, Р.Р. Валиев ${ }^{1,3}$ \\ ${ }^{1}$ Санкт-Петербургский государственный университет, \\ Санкт-Петербург, Россия \\ ${ }^{2}$ Институт проблем машиноведения РАН, \\ Санкт-Петербург, Россия \\ ${ }^{3}$ Уфримский государственный авиационный технический университет, \\ Уфа, Россия \\ E-mail: ad.evstifeev@gmail.com
}

(Поступила в редакцию 11 мая 2018 г.)

\begin{abstract}
Проведено изучение прочностных и эрозионных свойств титанового сплава Ti-6Al-4V в состоянии поставки и подвергнутого обработке методом равноканального углового прессования. Ультрамелкозернистый материал был испытан наряду с исходным на динамическое растяжение с использованием башенного копра Instron и в эрозионной установке аэродинамического типа в воздушном потоке с частицами корунда в качестве абразивного материала. Несмотря на существенное увеличение статических прочностных свойств ультрамелкозернистый материал продемонстрировал схожие свойства с исходным материалом в условиях динамических нагрузок, что в свою очередь проанализировано на основе структурно-временного подхода с использованием критерия инкубационного времени.
\end{abstract}

Работа выполнена при финансовой поддержке гранта РНФ (№ 17-79-10145). Авторы Н.А. Казаринов и P.P. Валиев выражают благодарность гранту СПбГУ Мероприятие 3 (id: 26130576) за подготовку раздела 2. Экспериментальные исследования проведены с использованием оборудования лаборатории СПбГУ „Механики перспективных массивных наноматериалов для инновационных инженерных приложений“, ресурсных центров Научного парка СПбГУ „Исследование экстремальных состояний материалов и конструкций“ и „Рентгенодифракционные методы исследования“.

DOI: 10.21883 /FTT.2018.12.46719.132

\section{1. Введение}

Испытания материалов для применения в авиастроительной отрасли включают в себя определенное количество экспериментов в квазистатических режимах и некоторые узкоспециализированные эксперименты, наиболее приближенные к условиям эксплуатации. К примеру, тестирование материалов, используемых при изготовлении турбинных лопаток компрессорных двигателей, включает серию эрозионных экспериментов. Различие в материалах выражается как правило в численном отличии между уносом массы материала с образца после испытаний с заданной длительностью. При этом остается неизученным поведение материала в условиях нагрузок, отличающихся от модельных. Важной характеристикой в этом случае может служить величина пороговых характеристик внешнего воздействия и численный анализ свойств материала с использованием методов и критериев динамической механики разрушения [1].

Другим аспектом в выборе материала для практического применения является возможность улучшения его прочностных и эксплуатационных свойств. Одним из перспективных методов изменения свойств материала является создание ультрамелкозернистой (УМЗ) структуры методами интенсивной пластической деформации (ИПД). Это направление является предметом исследований во всем мире [2]. Исследовано влияние изменения структуры материала на статическую прочность [3], пластичность, усталостную прочность [4], адгезию защитных покрытий [5]. Представленные исследования демонстрируют перспективность ИПД обработки в части повышения прочностных и эксплуатационных свойств материалов для практического применения.

Повышение прочностных и эксплуатационных характеристик материала, применяемого в экстремальных условиях, невозможно без экспериментального и теоретического изучения их динамических прочностных свойств. В работе приводятся результаты исследований титанового сплава Ti-6Al-4V, применяющегося для изготовления целого ряда важных конструктивных элементов в аэрокосмической отрасли [6,7]. Прочностные и эксплуатационные свойства в работе проанализированы с использованием структурно временного подхода в механике разрушения при учете параметров материала, полученных в ходе эрозионных и ударных экспериментов.

\section{2. Материал}

Микроструктура исходных заготовок диаметром $20 \mathrm{~mm}$ состояла из равноосных зерен $\alpha$-фазы со средним размером $15 \mu \mathrm{m}$. С целью формирования в заготовках бимодальной (смешанной глобулярно-пластинчатой) микроструктуры заготовки были подвергнуты термо- 


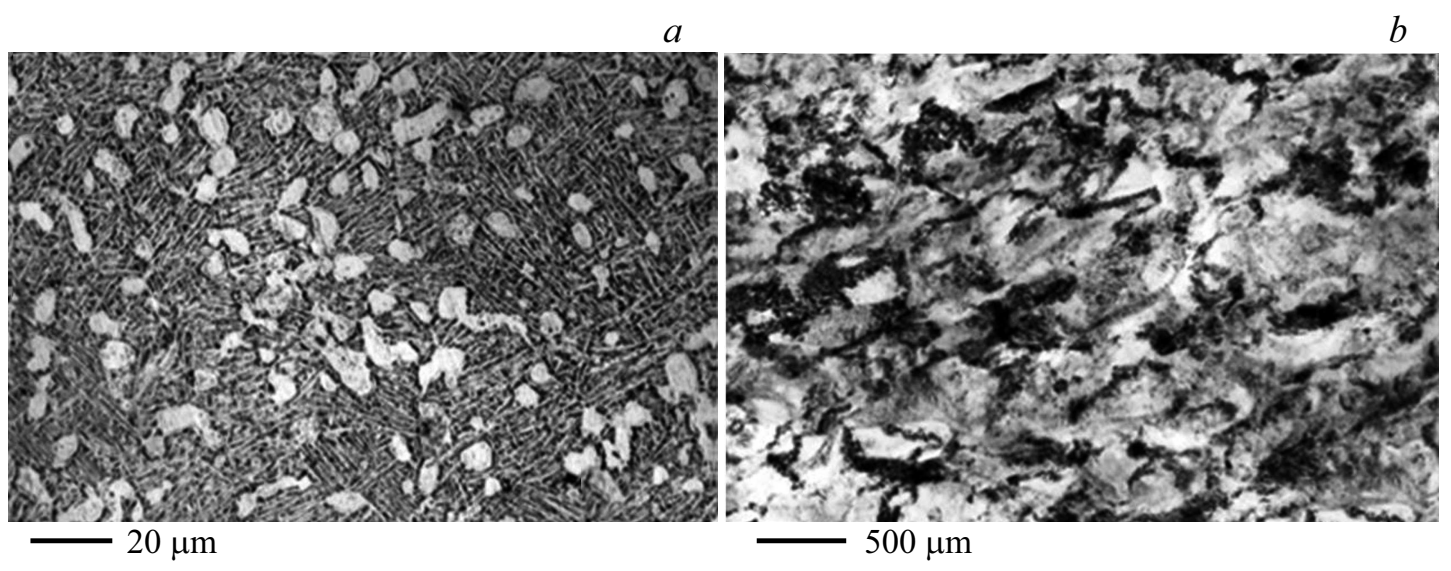

Рис. 1. Структура образцов титанового сплава Ti-6Al-4V: $a-$ в исходном состоянии; $b-$ в УМЗ состоянии.
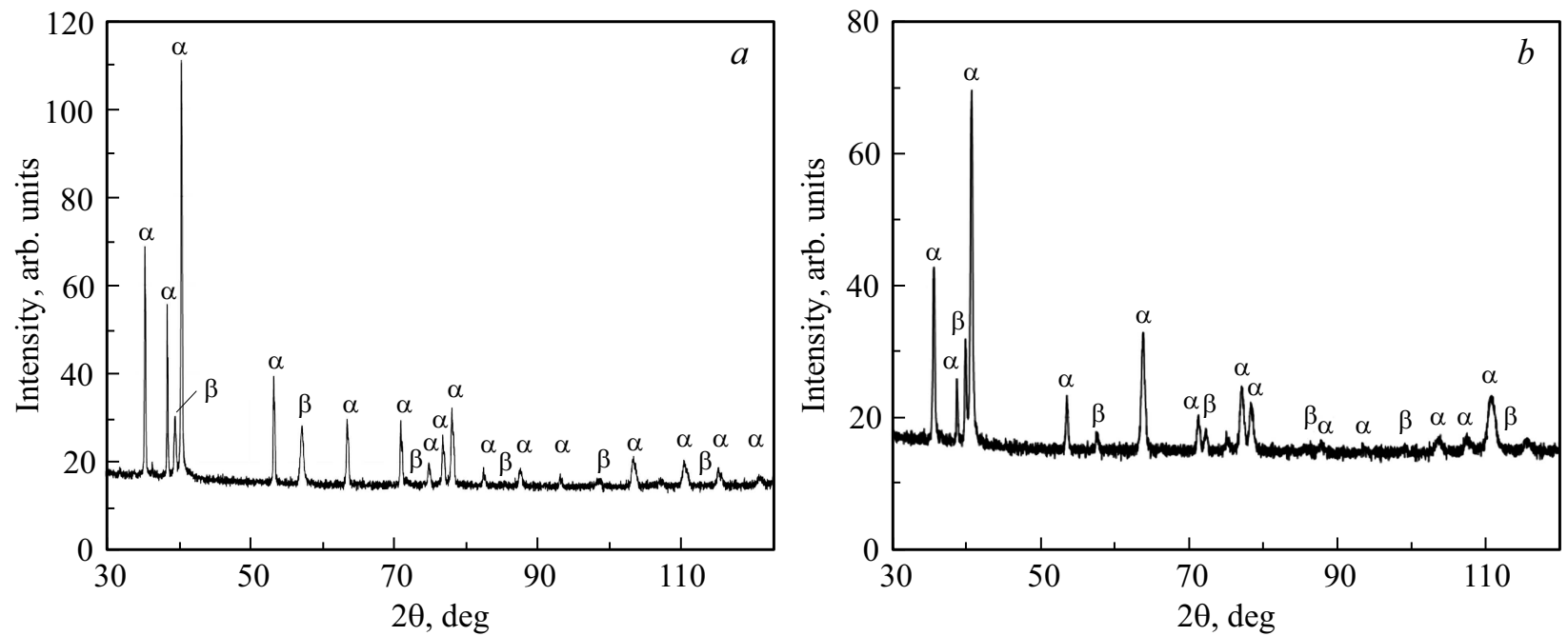

Рис. 2. Рентгенограмма образцов титанового сплава Ti-6Al-4V: $a-$ в исходном состоянии; $b-$ в УМЗ состоянии.

обработке (ТО), включающей закалку с температуры $975^{\circ} \mathrm{C}$ в воду с последующим отжигом при температуре $675^{\circ} \mathrm{C}$ в течение $4 \mathrm{~h}$. Для формирования УМЗ-структуры исходные заготовки были подвергнуты комбинированной деформационно-термической обработке. При равноканальном угловом прессовании (РКУП) [8-10] был использован маршрут $B c$, при котором после каждого прохода заготовка поворачивается на $90^{\circ}$ вокруг своей продольной оси. В процессе прессования при температуре $600^{\circ} \mathrm{C}$ материал продавливался в специальной оснастке через два канала диаметром $20 \mathrm{~mm}$, пересекающихся под углом $120^{\circ}$. Для снятия деформационных напряжений был произведен последующий отжиг при $500^{\circ} \mathrm{C}$ в течение одного h.

На рис. 1, а представлена исходная микроструктура сплава ВТ6 по данным растровой электронной микроскопии. Показано наличие $\beta$-превращенной ламеллярной структуры со средним размером вторичной $\alpha$-фазы $1 \mu \mathrm{m}$ и зерен первичной $\alpha$-фазы размером около $8 \mu \mathrm{m}$, объемная доля которой не превышает $25 \%$. На рис. $1, b$ представлена типичная УМЗ-структура со средним размером зерен $\alpha$ - и $\beta$-фазы $250 \mathrm{~nm}$, формируемая в сплаве ВТ6 после обработки методом РКУП с последующим отжигом.

На рис. 2 представлены типичные рентгенограммы титанового сплава в исходном и ультрамелкозернистом состояниях.

Обработка РКУП привела к увеличению микротвердости по Викерсу на $11 \%$ с $321 \pm 1.8$ до $356 \pm 3.8 \mathrm{Hv}$. Предел кратковременной прочности увеличился на $33 \%$ с $950 \pm 30$ до $1200 \pm 40 \mathrm{MPa}$.

\section{3. Методика испытаний на растяжение и результаты}

Для выполнения экспериментов на растяжение были использованы установка Shimadzu AG-50kNX для растяжения в квазистатических режимах, и установка Instron CEAST 9350 для реализации ударных растягивающих нагрузок при скорости деформации порядка $10^{2}-10^{3} \mathrm{~s}^{-1}$. 


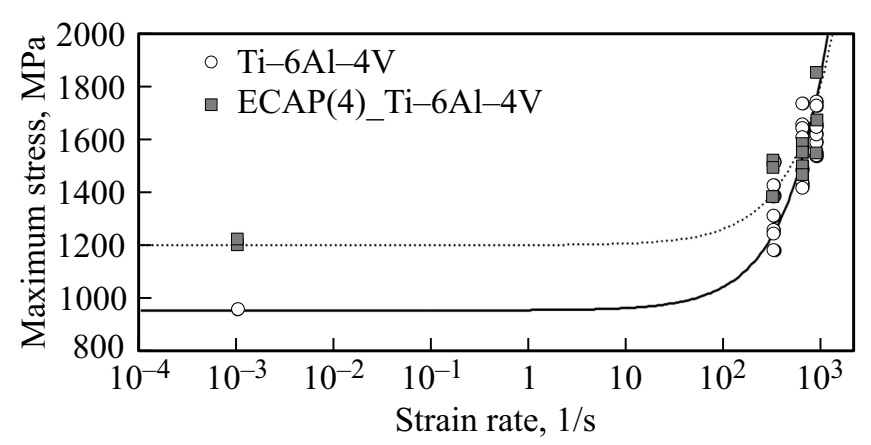

Pис. 3. Зависимость прочности на растяжение от скорости деформации для Ti-6Al-4V в исходном и УМЗ состоянии. Динамические кривые прочности построены по критерию (1) с параметрами материала: для исходного сплава $E=115 \mathrm{GPa}, \tau_{c}=16 \mu \mathrm{s}, \sigma_{c}=950 \mathrm{MPa}$; для УМЗ-сплава $E=115 \mathrm{GPa}, \tau_{c}=10 \mu \mathrm{s}, \sigma_{c}=1200 \mathrm{MPa}$.

Геометрические размеры образцов были выбраны исходя из структурных особенностей получаемых объемных наноструктурированных материалов и ограничений по допустимой нагрузке используемых испытательных машин. Длина рабочей части образцов $5 \mathrm{~mm}$, ширина $2 \mathrm{~mm}$. Образцы вырезались с использованием электроэрозионного станка ARTA 123 PRO с высокой точностью и доводились на полировальном круге до единых параметров шероховатости. Подробнее методика проведения экспериментальных исследований на растяжение при помощи башенного копра приведена в следующих работах [11-12].

Экстремальные значения максимальных значений напряжений для исследуемых материалов в зависимости от скорости деформации представлены на рис. 3. Полученные результаты демонстрируют, что в условиях квазистатических нагрузок сплав в исходном состоянии имеет меньшую прочность чем сплав в ультрамелкозернистом состоянии. С ростом скорости деформации различия нивелируются и два материала демонстрируют равные прочностные характеристики.

Отмеченные особенности поведения материала при высоких скоростях деформации можно объяснить с применением структурно временного подхода. В качестве критерия разрушения материала при растяжении выберем критерий инкубационного времени $[13,14]$ :

$$
\frac{1}{\tau_{c}} \int_{t-\tau_{c}}^{t} \frac{\sigma(s)}{\sigma_{c}} d s \leq 1,
$$

где $t$ - время, $\sigma$ - зависимость разрывающего напряжения от времени, $\sigma_{c}-$ статический предел прочности при растяжении, $\tau_{c}-$ инкубационное время разрушения, являющейся мерой прочности в динамическом диапазоне параметров внешнего воздействия. Константы $\sigma_{c}$ и $\tau_{c}$ являются параметрами материала. В качестве модельного разрывающего напряжения выберем линейно возрастающее во времени, что наиболее приближенно к условиям эксперимента.
С использованием критерия инкубационного времени и экспериментальных данных были определены параметры материала для исходного сплава $E=115 \mathrm{GPa}, \tau_{c}=16 \mu \mathrm{s}, \sigma_{c}=950 \mathrm{MPa} \mathrm{и} \mathrm{для} \mathrm{УМЗ-спла-}$ ва $E=115 \mathrm{GPa}, \tau_{c}=10 \mu \mathrm{s}, \sigma_{c}=1200 \mathrm{MPa}$. Скоростные кривые прочности, построенные с учетом параметров материалов, представлены на рис. 3. С ростом скорости деформации наблюдается нелинейное увеличение максимальных растягивающих напряжений при растяжении. При этом экспериментальные результаты в динамическом диапазоне параметров нагружения можно объяснить уменьшением величины параметра инкубационного времени, который отвечает за динамическую прочность. Уменьшение динамической прочности в титановом сплаве Ti-6Al-4V после РКУП-обработки рядом авторов объясняется снижением пластических свойств материала из-за формирования сложной структуры с высокой плотностью дислокаций и внутренними напряжениями [15], что также подтверждает увеличение внутренних микроискажений кристаллической решетки, определенных в ходе рентгеноструктурного анализа.

Численный анализ экспериментальных данных на растяжение титановых сплавов в двух состояниях позволяет сделать вывод о повышении прочностных характеристик титанового сплава Ti-6Al-4V (после РКУП-обработки) в квазистатических условиях нагружения при сохранении прочностных свойств в динамическом диапазоне нагрузок. В рамках авиастроения данные результаты могут стать принципиально важными в части выбора материала для ответственных динамически нагруженных узлов. Результаты вышеприведенных испытаний могут быть эффективно применены для прогнозирования разрушения, сопровождающего эрозионный процесс [16]. К примеру, можно рассмотреть поведение УМЗ титанового сплава Ti-6Al-4V в условиях работы компрессорных лопаток турбинных двигателей. Как известно, турбинные лопатки испытывают высокоскоростные эрозионные воздействия от пылевых частиц. При этом стоит отметить, что эрозионное воздействие по своей сути является динамической нагрузкой, так как удары мелких частиц приводят к коротким импульсным воздействиям на поверхность материала.

\section{4. Методика эрозионных испытаний и результаты}

Образцы сплава Ti-6Al-4V в исходном и в ультрамелкозернистом состоянии были испытаны попарно в условиях эрозионного потока для двух порошков со средним размером фракций 109 и $230 \mu \mathrm{m}$ соответственно. Для испытаний была выбрана фиксированная концентрация твердых частиц в потоке - $1.7 \mathrm{~g} / \mathrm{s}$. Каждая пара образцов испытывалась в течение $5 \mathrm{~min}$. Экспериментальная схема [17] аэродинамической установки представлена на рис. 4.

В качестве параметров, отвечающих за разрушение, использовались изменение массы образца (рис. 5) и 


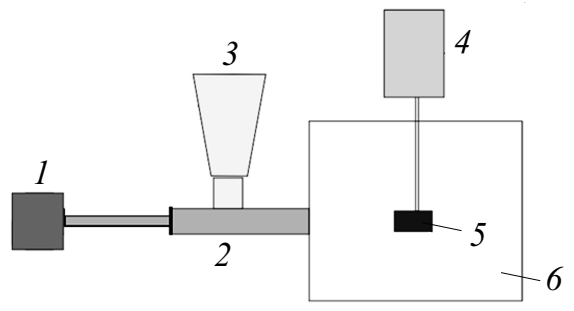

Pис. 4. Схема эрозионной установки $(1-$ компрессорная камера; 2 - разгонный участок; 3 - дозатор твердой фазы; 4 - пневматический привод для ввода образца; 5 - образец; 6 - рабочая камера).

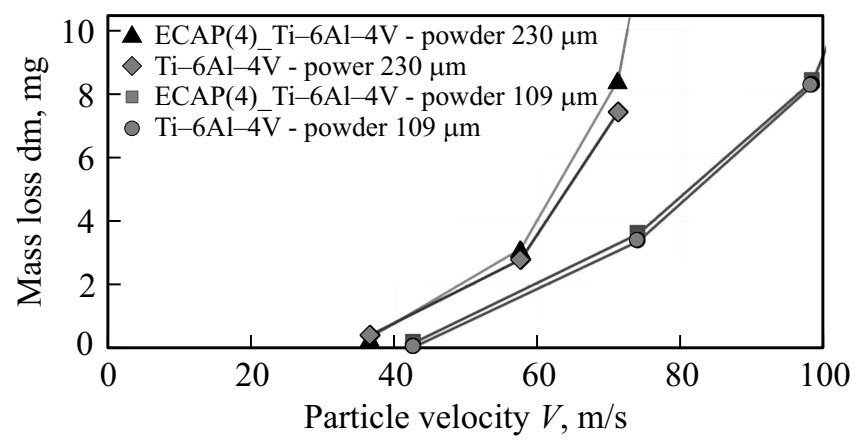

Рис. 5. Изменение массы образцов титанового сплава Ti-6A1-4V в исходном и УМЗ состоянии (ЕСАР) после эрозионного испытания с размерами твердой фракции в воздушном потоке 109 и $230 \mu \mathrm{m}$ соответственно.

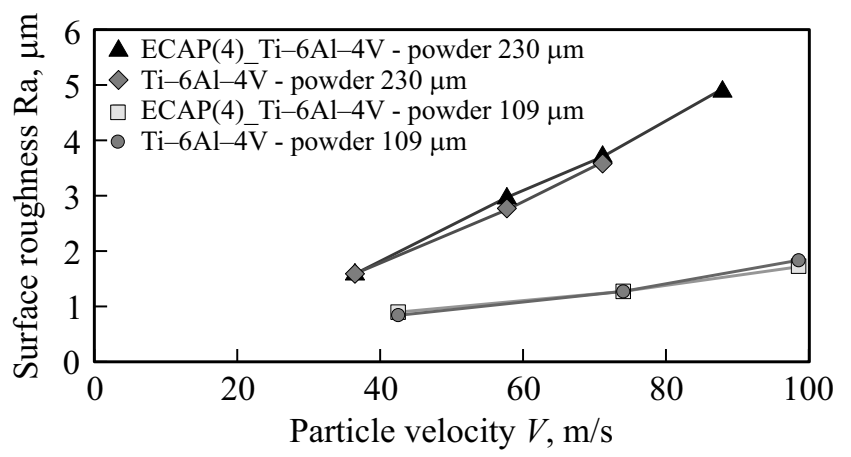

Рис. 6. Шероховатость поверхности образцов титанового сплава Ti-6Al-4V в исходном и УМ3-состоянии (ЕСАР) после эрозионного испытания с размерами твердой фракции в воздушном потоке 109 и $230 \mu \mathrm{m}$ соответственно.

шероховатости поверхности (рис. 6). Шероховатость поверхности определялась профилометром Surftest sj-210 с возможностью автоматизированного расчета среднего арифметического отклонения точек профиля шероховатости от средней линии ( $\mathrm{Ra})$.

Результаты эрозионных экспериментов демонстрируют схожие свойства титанового сплава Ti-6Al-4V в исходном и УМЗ-состояниях. Поскольку удары частиц о поверхность оказывают высокоскоростное импульсное воздействие, динамической нагрузкой, можно провести корреляцию с данными о поведении исследуемых материалов в условиях динамических растягивающих нагрузок. Тем самым, эрозионная стойкость материала в условиях высокоскоростных импульсных воздействиях может быть объяснена динамической прочностью материала.

В качестве практических результатов выполненного исследования можно отметить повышенные прочностные и хорошие эксплуатационные характеристики титанового сплава Ti-6Al-4V после ИПД-обработки методом РКУП, связанные с сохранением эрозионной стойкости нового материала.

\section{5. Заключение}

С использованием структурно временного подхода и результатов выполненных экспериментов по растяжению было показано наличие двух ветвей на скоростной зависимости прочности, отвечающих за поведение материала в условиях статических и динамических нагрузок. В статической области деформирования УМЗ-материал продемонстрировал большую на 33\% прочность в сравнении с исходным материалом. При этом с ростом скорости деформирования различия нивелировались. С точки зрения структурно-временного подхода это можно объяснить снижением величины параметра инкубационного времени при ИПД-обработке. Снижение пластических свойств материала связано с формированием новой структуры в материале с высокой плотностью дислокаций и внутренними напряжениями.

Выполненные исследования показали, что методами ИПД возможно повышение прочностных характеристик титанового сплава Ti-6Al-4V в условиях квазистатических нагрузок с сохранением достаточной прочности в условиях динамических нагрузок. Это было экспериментально подтверждено в условиях динамического растяжения и высокоскоростной эрозии. Также стоит отметить, что разработка и внедрение новых материалов требует экспериментально-теоретического изучения прочностных и эксплуатационных свойств материалов в широком диапазоне изменения параметров внешнего воздействия.

\section{Список литературы}

[1] Yu.V. Petrov, V.I. Smirnov. Tech. Phys. 55, 230, (2010).

[2] R. Valiev. Nature Mater. 3, 511, (2004).

[3] Q. Wei, H.T. Zhang, B.E. Schuster, K.T. Ramesh, R.Z. Valiev, L.J. Kecskes, R.J. Dowding, L. Magness, K. Cho. Acta Mater. 54, 4079 (2006).

[4] Y. Estrin, A. Vinogradov. Int. J. Fatigue 32, 898 (2010).

[5] C.T. Wang, N. Gao, M.G. Gee, R.J. Wood, T.G. Langdon. J. Mater. Sci. 48, 4742, (2013).

[6] M. Peters, J. Kumpfert, C.H. Ward, C. Leyens. Adv. Eng. Mater. 5, 419, (2003).

[7] G. Welsch, R. Boyer, E.W. Collings. Materials properties handbook: titanium alloys. ASM international (1994). 
[8] R.Z. Valiev, R.K. Islamgaliev, I.V. Alexandrov. Progr. Mater. Sci. 45, 103, (2000).

[9] I.P. Semenova, M.K. Smyslova, K.S. Selivanov, R.R. Valiev, Y.M. Modina. In IOP. Conf. Ser.: Mater. Sci. Eng. 194, 012035, (2017);

[10] I.P. Semenova, A.V. Polyakov, V.V. Polyakova, Y. Huang, R.Z. Valiev, T.G. Langdon. Adv. Eng. Mater. 18, 2057, (2016).

[11] A.D. Evstifeev, A.A. Chevrychkina, Y.V. Petrov. Mater. Phys. Mech. 32, 258, (2017).

[12] A.D. Evstifeev. J. Phys.: Conf. Ser. 991, 012019, (2018).

[13] Y.V. Petrov, A.A. Utkin. Sov. Mater. Sci. 25, 153, (1989).

[14] Y.V. Petrov, N.F. Morozov. ASME J. Appl. Mech. 61, 710, (1994).

[15] Л.Р. Саитова, И.П. Семенова, И.В. Александров. Вестн. Самарского гос. техн. ун-та. Сер. физ.-мат. науки 27, 164, (2004).

[16] Y.V. Petrov, A.M. Bragov, N.A. Kazarinov, A.D. Evstifeev. Phys. Solid State, 59, 93, (2017).

[17] A. Evstifeev, N. Kazarinov, Y. Petrov, L. Witek, A. Bednarz. Eng. Failure Anal. 87, 15, (2018).

Редактор Т.Н. Василевская 